\title{
Advance praise for Making a Difference
}

In the wake of the Covid pandemic, there is a critical need for a generous sharing of energy and expertise as we all seek to understand how we can work in the 'new normal'. For those with energy, valuable skills and appropriate expertise, volunteering as an independent director is an effective way of giving for the collective good. In this book, Gerry Brown sets out the role of independent directors: how talented and informed volunteers can contribute as counsellors, guides and mentors in helping organisations steer strategy, manage risk, ensure accountability and deliver to stakeholders. In his eloquent, succinct and pragmatic style, Gerry explains the why, what and how. Why become an independent director? What's involved? What are the challenges and opportunities? How to choose and approach organisations? Why me? What does it take? There is no better time, or more important time, to step forward and share our energy, expertise and wisdom to help organisations, businesses and society move forward in the new world.

- Professor Malcolm Kirkup

Pro Vice Chancellor, University of Westminster

Head, Westminster Business School

If you are considering becoming an independent director (or governor) of a business, charity, educational establishment, sports body or similar, then Gerry Brown's book is an essential read. Drawing on his own extensive experience and through interviews with a variety of successful IDs, he explains why there is a need for more diverse boards which can provide sound governance in today's complex and fast moving world. Equally for the experienced chair or board member, this book serves as an outstanding guide to best practice governance.

In my role as the Further Education Commissioner for England I have learned how important good governance is, both within colleges and elsewhere in business, charities and beyond. The best boards that I have encountered always include a diverse range of independent directors, an open culture led by the chair, and a willingness to both support and challenge the executive. Gerry Brown's excellent book is the perfect guide for anyone considering joining a governing body as an independent director, as well as being a best practice guide for existing chairs and IDs. As organisations rebuild after the impact of the pandemic, there has never been a more important time to provide good governance.

- Richard Atkins, Further Education Commissioner, Council Member, The University of Exeter 
Gerry Brown is a passionate advocate of board room diversity.

Not only that, he challenges us all to take on one of these roles, and see it as a means to make a much wider contribution to society; a way of growing our life experience. He is very persuasive, with many real world examples.

But this is a book full of realism as well. Rightly he points out that no one is going to be appointed first time as an FT-100 non-executive. But your contribution will be fulfilling not just to you, but to society more widely. It can be the first rung on a ladder to bigger things.

The book is also practical. It advises those entering this world, at whatever level, how to approach your first meeting and how to grow in the role. It makes it clear that the job can involve difficult decisions - whether to fire the chairman or the CEO could be one of them.

One thing is clear, with all the challenges that we face, we need a breath of fresh air in our board rooms whether local or national, charity or business. That diverse talent is out there. Gerry Brown's strong advocacy is a means of making it happen.

- Lord Robin Teverson, former Member of the European Parliament 
To my brother Ben, who has been an inspiration to everyone through his charitable work for the mentally handicapped despite his own illness. He is a living example of Making a Difference. 
